\title{
Perceptions of Mobile Apps for Smoking Cessation Among Young People in Community Mental Health Care: Qualitative Study
}

Minda A Gowarty ${ }^{1,2,3}$, MD; Nathan J Kung², BA; Ashley E Maher ${ }^{2}$, BA; Meghan R Longacre ${ }^{2,4}$, PhD; Mary F Brunette $^{2,3,5}, \mathrm{MD}$

\footnotetext{
${ }^{1}$ Departments of Internal Medicine and Community and Family Medicine, Dartmouth Hitchcock Medical Center, Lebanon, NH, United States

${ }^{2}$ Geisel School of Medicine at Dartmouth, Hanover, NH, United States

${ }^{3}$ Center for Technology and Behavioral Health, Geisel School of Medicine at Dartmouth, Lebanon, NH, United States

${ }^{4}$ The Dartmouth Institute for Health Policy and Clinical Practice, Geisel School of Medicine at Dartmouth, Hanover, NH, United States

${ }^{5}$ Department of Psychiatry, Dartmouth Hitchcock Medical Center, Lebanon, NH, United States
}

Corresponding Author:

Minda A Gowarty, MD

Departments of Internal Medicine and Community and Family Medicine

Dartmouth Hitchcock Medical Center

1 Medical Center Drive

Lebanon, NH, 03756

United States

Phone: 16036536868

Email: minda.a.gowarty@hitchcock.org

\section{Abstract}

Background: Young adults with serious mental illness are over twice as likely to have tobacco use disorder than those in the general population and are less likely to utilize proven treatment methods during quit attempts. However, little research has evaluated the efficacy of interventions for this group. Smartphone apps may be an underutilized tool for tobacco use disorder among young adults with serious mental illness.

Objective: The aim of this study was to explore attitudes toward smoking cessation apps and preferences regarding app design in young adult smokers with serious mental illness.

Methods: Five focus groups involving 25- to 35-year-old adults with serious mental illness receiving treatment at a community mental health center were conducted between May 2019 and August 2019. Three researchers independently coded transcripts and identified themes using thematic analysis.

Results: Participants ( $\mathrm{n}=22)$ were individuals who smoke daily: $10(46 \%)$ self-identified as female, 18 (82\%) self-identified as White, and $9(41 \%)$ had psychotic disorders. Key themes that emerged included a general interest in using health apps; a desire for apps to provide ongoing motivation during a quit attempt via social support, progress tracking, and rewards; a desire for apps to provide distraction from smoking; concerns about app effectiveness due to a lack of external accountability; and concerns that apps could trigger cravings or smoking behavior by mentioning cigarettes or the act of smoking.

Conclusions: Apps have the potential to support smoking cessation or reduction efforts among young adults with serious mental illness. However, they may require tailoring, optimization, and clinical support to effectively promote cessation in this population.

(JMIR Form Res 2020;4(10):e19860) doi: 10.2196/19860

\section{KEYWORDS}

smoking cessation; mHealth; serious mental illness; smartphone application; digital health; psychiatric illness; tobacco treatment

\section{Introduction}

People with serious mental illness (disabling mood, anxiety, and psychotic disorders) are more likely to develop tobacco use disorders and are less likely to quit smoking than those in the

general population, even when using recommended cessation interventions [1-3]. Tobacco smoking is a major contributor to high rates of chronic cardiovascular and lung diseases, high treatment costs (US $\$ 160$ billion per year in the United States [4]), and to a 10- to 20-year reduction in life expectancy for people with serious mental illness [2,5-7]. While quitting 
smoking at any age confers health benefits, the harmful health effects of smoking worsen as the number of cigarettes and duration of smoking increase [8]. Intervening at an early age can dramatically reduce the risk of smoking-related disease and can mitigate early mortality [8].

A significant body of literature [9-12] has described unique challenges faced by people with serious mental illness who wish to quit smoking, which include both sociocultural influences (such as lower education and income, as well as higher stress levels) and neurobiological influences (including the modulating effect of nicotine on dopaminergic pathways in schizophrenia). Additionally, people with serious mental illness may endorse using tobacco to manage challenging psychiatric symptoms and to overcome difficulties with socialization $[10,12,13]$. Furthermore, some cessation medications (eg, bupropion) may not be indicated for a subset of people with serious mental illness [14]. While overall, pharmacologic therapies are safe and effective for people with psychiatric illnesses [3,11,15-17], behavioral interventions are also needed to teach cessation skills, provide education about the safety and efficacy of smoking cessation medications, and support mental health. However, little research has focused on interventions for young adults with serious mental illness and tobacco use disorder, and effective strategies for addressing tobacco use disorder among young adults with serious mental illness have not yet been established.

Research on treatment in the general population is informative. Behavioral therapies for treating tobacco use disorder improve abstinence rates in youth and young adults in the general population, and are recommended by US Clinical Practice Guidelines [18]. A meta-analysis [19] that extracted data for young adult participants (18 to 24 years old) from studies of adult smokers found that behavioral interventions designed for older age groups were also effective for young adults. Research on interventions designed specifically for young adults found the most promising results from telephone and web-based interventions [20]. Yet evidence-based, scalable tobacco use disorder treatment approaches, such as telephone Quitline counseling, are underutilized by young people. For example, only $8.5 \%$ of US Quitline callers from 2011 to 2013 were young adults [21], and that percentage decreased to 5\% in 2016 [22]. Young adults with and without serious mental illness report frequent quit attempts [23], but they are typically unaided and unsuccessful [24]. In our previous research [25], we found that young adults with serious mental illness, in contrast to middle-aged adults with serious mental illness, were less likely to initiate evidence-based tobacco use disorder treatment after education or standard motivational interviewing, suggesting that more appealing approaches to treatment are needed for this group.

Young people are avid users of smartphone technology [26], and smartphone apps offer beneficial features for behavioral intervention delivery. App content can be accessed on-demand, allowing users to capitalize on fleeting moments of motivation. Additionally, apps can deliver personalized and interactive content, including proactive notifications based on time and location [27]. In a recent survey [28], we found that $80 \%$ of young people with serious mental illness used smartphones, similar to the overall rate among young adults with low incomes (in the United States) [26]. Furthermore, 70\% of young adults with serious mental illness were willing to try digital health interventions on their device [28], indicating preliminary feasibility for digital interventions for tobacco use disorder treatment in this group.

While smartphone apps offer a number of attributes that seem well-suited to young adults with and without serious mental illness, optimal development and implementation of this technology requires input from the intended users. However, phase I (design and refinement) and phase II (feasibility, proof-of-concept, or pilot testing) trials of smoking cessation apps are often omitted or are not reported in published literature [29]. Assessing end users' desires regarding app content and features is important in developing appealing interventions as well as for cost-effective implementation and reliable interpretation of effectiveness [29]. Recent work has addressed this gap in knowledge for middle aged adults with serious mental illness [30-33]. However, to our knowledge, research evaluating perceptions of apps for smoking cessation among young adults with serious mental illness has not been published.

Given the need for improved engagement in tobacco treatment among young adults with serious mental illness, and the promise of smartphone apps as an accessible and tailorable vehicle for behavioral intervention, we sought to explore attitudes among young adults with serious mental illness who smoke toward using apps for smoking cessation as well as preferences regarding app design. The goal of this study was to obtain information that could guide the tailoring of mobile app interventions to the unique needs of this population.

\section{Methods}

\section{Participants and Recruitment}

We used purposive sampling to recruit potentially eligible participants from a single large community mental health center in New England between May 2019 and August 2019. Recruitment occurred via flyers posted in waiting rooms and clinician referral. Eligible participants were 18 to 35 years old, English-speaking, stable in their outpatient mental health treatment for serious mental illness (ie, no hospitalization in past 30 days per chart review), and smoked daily. We chose the age range of 18 to 35 years to focus on adults for whom quitting smoking has the greatest potential long-term mortality benefit. While the National Young Adult Health Survey found that cessation attitudes were similar among 18- to 24-year-old and 25- to 34-year-old adults [34], it also demonstrated that smoking trajectories differ between these age groups [35]. Thus, we stratified patients by age into 2 groups -18 to 24 years and 25 to 35 years-to better characterize participants' cessation needs. This paper presents findings from the 25 to 35-year-old age group. Patients were excluded if they were pregnant or had a current, unstable substance use disorder (per chart review or per the participant's mental health center clinician).

Prior to each focus group, research staff read the study information sheet aloud with the participants and discussed the purpose of the study with them. All eligible participants were 
deemed competent to give consent, which participants provided verbally. Participants received a US \$30 gift card to a retail store after completing the focus group. The New Hampshire State Institutional Review Board approved and monitored all study activities.

\section{Procedures}

\section{Brief Survey}

Participants completed a 10-item survey prior to the start of focus group discussions. The survey included questions about the participants' gender identity, race, tobacco use, and technology use. Technology use included questions about app use, including whether participants had ever downloaded a health-related app (such as a step tracker or stress management app). Participants' DSM-5 (Diagnostic and Statistical Manual of Mental Disorders, Fifth Edition) psychiatric diagnoses, as determined by their mental health center clinicians, were gathered by chart review.

\section{Focus Groups}

We conducted 5 focus groups between May 2019 and August 2019, each of which included 3 to 6 participants and lasted approximately one hour. A researcher trained in qualitative methods (MG) moderated the focus groups, with a second member of the research team present to take field notes. Focus groups took place at the community mental health center where participants received services.

The moderator posed questions in a funnel-type structure [36], starting with broad questions about participant experiences with smoking, narrowing to experiences with quitting or reducing smoking, and finally to perceptions about using smartphone apps to quit or reduce smoking. We followed a semistructured format, using probing and clarifying questions to elicit thick descriptions of participants' perceptions and experiences. The focus group discussions were audiorecorded and transcribed. A member of the research team who was present at the focus groups compared the transcriptions to the audio files to ensure accuracy. Focus groups were conducted until thematic saturation was reached, which was identified when previously recognized themes repeated without the emergence of new themes [37,38]. This occurred after the fifth focus group. The focus group discussion guide can be found in Multimedia Appendix 1.

\section{Data Analysis}

Transcripts were iteratively analyzed using thematic analytic techniques [39]. Three researchers (MG, NK, and AM) independently coded each transcript using ATLAS.ti (version 8, ATLAS.ti Scientific Software Development GmbH). After conducting an immersive review of the data set, an initial set of codes was generated using a deductive-inductive approach. This approach allowed us to generate codes based on prior empirical data on facilitators and barriers to quitting smoking, while also allowing new codes to emerge from the data set. The 3 researchers met regularly to refine the code definitions until reaching a final code structure, which they each independently applied to the entire data set. Additional meetings were held to discuss discrepancies in applying the final codes to the data set until consensus was reached through negotiation [40]. Memoing was used throughout the coding process to facilitate a deeper understanding of how the codes relate to each other, and how codes could be represented by unifying themes [41]. The themes were then developed into thematic statements, and emblematic quotations where chosen to illustrate how the themes developed from the data. Negative case analysis was used to ensure the entire data set was represented in the emerging themes.

\section{Results}

\section{Study Participants}

Participants $(n=22)$ were individuals who smoked daily and who were stable in their community mental health treatment. Almost half of participants $(10 / 22,46 \%)$ self-identified as female, most $(18 / 22,82 \%)$ self-identified as white, and 9/22 $(41 \%)$ were diagnosed with psychotic disorders. Technology use data are presented in Table 1. 
Table 1. Focus group participant characteristics.

\begin{tabular}{ll}
\hline Characteristic & Value, $\mathrm{n}(\%)$ \\
\hline Demographic and clinical characteristics (n=22) & $12(54)$ \\
Gender & $10(46)$ \\
Male & $18(82)$ \\
Female & $3(14)$ \\
Race & $1(5)$ \\
$\quad$ White & $9(41)$ \\
Mixed & $(14)$ \\
I don't know & $18(95)$ \\
Psychotic disorder diagnosis & $18(95)$ \\
Technology use characteristics $\left(\mathbf{n}=\mathbf{1 9}^{\mathbf{a}}\right)$ & $16(84)$ \\
Use internet $\geq$ twice daily & $15(79)$ \\
Ever downloaded an app & \\
Ever downloaded a health app & \\
Would try an app if recommended by a doctor &
\end{tabular}

${ }^{\mathrm{a}}$ Technology use data were missing for 3 participants.

\section{Focus Group Themes}

\section{Facilitators and Barriers to Quitting Smoking}

During the initial discussions about reasons for smoking and participants' prior experiences with quitting, a number of themes emerged regarding facilitators and barriers to quitting. Reasons for quitting included the desire to save money and concern regarding their children's, pets', and personal health. For example, one participant stated:

\section{Ifeel like whenever I quit smoking, I can smell things easier, I can taste things more, and I can breathe better. [Group 1 Participant 3]}

Commonly cited reasons to continue smoking despite a desire to quit included addiction to nicotine, smoking as routine, and smoking to manage mental health symptoms (such as stress, anxiety, and depression):

...since I have bipolar, it helps. Smoking helps me not have so much anxiety, but when I do quit, I get even more. [Group 5 Participant 1]

Relapse triggers included socializing with other smokers, smelling tobacco smoke, and seeing people smoke on television or in movies. Of note, while many participants mentioned prior use of nicotine replacement therapy or cessation medications such as varenicline or bupropion with varying degrees of success, most stated that either they or their clinicians were not comfortable with using prescription cessation medications due to concern for psychiatric side effects. For example:
I took Chantix for a while...it really did help. I was smoking like two packs a day, and then when I was on the Chantix I was smoking maybe six cigarettes a day... and a doctor told me that it might contribute to depression. And I decided to get off it because I already have depression, and...I don't want to worsen it. [Group 4 Participant 1]
That's what I was told. None of my doctors, nobody will give me Chantix. Because of how bad I am. [Group 4 Participant 2]

\section{Role of Apps in Supporting a Quit or Reduction Attempt}

Focus group discussions regarding apps included participants' prior experiences with health-related apps as well as their perceptions regarding the role of smoking cessation apps. Their prior experiences were generally positive, though with variable effect on behavior. As participants discussed mobile apps for smoking cessation, many expressed interest in using apps during a quit attempt and described a number of ways that apps could offer support, such as providing motivation during a quit attempt, increasing awareness of smoking habits and money spent, and providing distraction from smoking. They also described app limitations, such as lack of external accountability and the potential to trigger cravings. These themes, along with illustrative quotations, are summarized in Table 2. Subthemes that emerged from these discussions are subsequenty presented. 
Table 2. Major themes regarding app use for smoking cessation, with corresponding illustrative quotations.

\begin{tabular}{|c|c|}
\hline Themes & Illustrative quotation \\
\hline \multicolumn{2}{|c|}{ Suggested ways apps could support a quit attempt } \\
\hline Providing ongoing motivation & $\begin{array}{l}\text { "I think it'd be cool if you can be able to, like, challenge someone else who was } \\
\text { trying to quit smoking, but like a buddy, right? But it's through the app. And they } \\
\text { could be thousands of miles away, but you got that one person..." [Group } 5 \text { Par- } \\
\text { ticipant 2] }\end{array}$ \\
\hline Increasing awareness of smoking patterns & $\begin{array}{l}\text { "Tracking when you smoke, the times you smoke, how much a day you smoke, } \\
\text { what led you to smoke that much. Like, I feel like those are all helpful things to } \\
\text { know" [Group } 4 \text { Participant 1] }\end{array}$ \\
\hline Providing distraction & $\begin{array}{l}\text { "Yeah, 'cause when you're having a craving, you just look at it [the app] and } \\
\text { maybe it'll tell you, like, uh, go for an hour run, or you know, tell you some sort } \\
\text { of structure to keep your mind off of you smoking. Something to keep you busy, } \\
\text { keep your hands busy..." [Group } 3 \text { Participant 1] }\end{array}$ \\
\hline \multicolumn{2}{|l|}{ App limitations in supporting a quit attempt } \\
\hline Lack of external accountability & $\begin{array}{l}\text { "...how is this going to know when I'm smoking a cigarette or not? I can just say } \\
\text { I'm not...and then I'll be sitting there smoking a cig, you know" [Group } 2 \text { Partic- } \\
\text { ipant 4] }\end{array}$ \\
\hline Possible triggers & $\begin{array}{l}\text { "You'd have to use, like a code word for cigarette so people don't think it in their } \\
\text { heads because once they think 'cigarette,' they're more likely to smoke" [Group } \\
2 \text { Participant 3] }\end{array}$ \\
\hline
\end{tabular}

\section{Prior Experiences With Apps}

Many participants described interest in health-related apps such as fitness trackers or mood trackers but noted varying degrees of benefit during their prior experiences with these types of apps. Participants discussed using the apps to review information about their personal habits (ie, their "stats"), but altering a behavior based on this feedback was rare. For example, a participant using a step tracker said,

\section{It was cool, a cool thing. It didn't really matter because I was working every day and I'd get about the same amount of steps every day. [Group 1 Participant 4]}

Only one participant described increasing her activity level to achieve goals in her step tracker; others simply reviewed their steps without this leading to change in behavior. Another participant found a symptom tracker useful to bring to her clinicians so they could change her treatment plan but did not utilize the information herself.

\section{Motivation}

Participants felt that while motivation to quit is a prerequisite for using a smoking cessation app, the app would need to provide features that could facilitate ongoing motivation. Participants suggested a number of ways that apps could motivate them, such as receiving support from other people within the app, feedback about progress (such as cigarettes avoided or money saved), and rewards such as financial incentives or badges. They also mentioned the importance of distraction to avoid cigarettes and suggested that an app could offer distraction by providing suggestions for alternate activities instead of smoking or by including games within the app.

\section{Social Support}

While one participant was concerned that an app would lead to missed social interactions and reduced social support for quitting, others discussed desire for the app to incorporate social support. Multiple participants suggested the ability to connect with other smokers for support within the app. One person suggested a chat feature:

So I think if you could, like, message someone on the app that's using it at the same time...if you could communicate with someone else using it, like chat with them... [Group 3 Participant 5]

Other participants recommended group challenges, similar to those seen in popular fitness apps:
I think it'd be cool if you can be able to, like, challenge someone else who was trying to quit smoking, but like a buddy, right? But it's through the app. And they could be thousands of miles away, but you got that one person... [Group 5 Participant 2]

While most of the participants who valued social support in their quit attempt mentioned other smokers or peers, one suggested involving family members as part of the quit plan in the app:
Or someone, a family member or a loved one, could work with the app and you could earn points or something like that by doing that more than smoking. [Group 2 Participant 3]

\section{Tracking Progress}

A prominent theme across focus groups was the desire to track the number of cigarettes smoked per day. Many participants wanted to track cigarettes to increase their awareness of how much they smoke. Others added that they would like to record additional information about their smoking so they could learn their typical smoking patterns:

Tracking when you smoke, the times you smoke, how much a day you smoke, what led you to smoke that 
much. Like, I feel like those are all helpful things to know. [Group 4 Participant 1]

Some participants noted that quitting all at once can feel insurmountable, but suggested that tracking cigarettes could be motivating by allowing them to see progress toward quitting:

\begin{abstract}
Maybe not to quit, because to me, quitting is not realistic. If I could reduce, like, instead of smoking 20 cigarettes, if I could smoke 5 cigarettes a day, that would've been a big difference. [Group 2 Participant 1]
\end{abstract}

Most participants cited money as a major motivator to quit or reduce their smoking and would want the app to provide a feature that tracks money spent on cigarettes or money saved by avoiding cigarettes:

I should, I feel like what'd probably help me, if like, if I kept track to see how much I'm paying, spending on them [cigarettes] because... if I kept track to see how much I'm paying every time, I'd be like, 'Okay, that needs to stop.' Because that's money that I could be using. [Group 4 Participant 3]

\section{Skills Training}

While tracking was a common theme, fewer participants suggested skill-based features for behavioral change. One participant recommended that an app include

Something to disassociate the triggers and patterns associated with smoking. [Group 1 Participant 5]

Another stated that

The app has to be informative. It should have tips on how to reduce the urge to smoke. [Group 2 Participant 1]

However, such statements were far less common than recommendations for tracking.

\section{Rewards}

A common theme across focus groups was the desire for rewards within the app. Some participants mentioned financial rewards such as gift cards for using the apps while others recommended that the app award badges for progress, based on their experience with other health behavior change apps:

I think that those badges, you know, when I get those rewards...nobody else sees them. I'm the only one, but it is a reward to myself...It's just mine. Nobody can take it from me. This is stuff that I worked hard for, and worked, probably, pretty hard for. [Group 5 Participant 2]

\section{Distraction}

Another prominently mentioned feature across focus groups was the benefit of distraction during a quit attempt. Many participants described using distraction as a tool for avoiding cigarettes during prior quit attempts and felt that a smartphone app would be well-suited to providing distraction. Some participants suggested that the app could provide games to play to avoid smoking. Others felt that the app could provide suggestions for alternative activities to smoking:
Yeah, 'cause when you're having a craving, you just look at it [the app] and maybe it'll tell you, like, uh, go for an hour run, or you know, tell you some sort of structure to keep your mind off of you smoking. Something to keep you busy, keep your hands busy... [Group 3 Participant 1]

\section{App Limitations}

Most participants felt that the biggest barrier to using an app to quit or reduce smoking was a lack of motivation to change smoking behavior in general, and that once motivated, there were few barriers other than practical issues related to any mobile technology (eg, limited phone battery, inability to use phone if lost or broken, limited cellular or wireless internet service in certain locations). However, two main concerns arose regarding the limitations of apps during a quit attempt—a lack of external accountability and the potential to trigger cravings.

A prominent theme across focus groups was the need for external accountability during a quit attempt and concern that an app would not be able to provide this. Related to their discussion of the importance of monitoring progress, participants voiced concerns about the temptation to report false information to an app. One participant, who had previously used a cigarette tracking app, noted:

\section{I tried a cigarette counter once, and realized it wasn't gonna work to help me quit smoking because I, at that time, I would cheat and not log all of my cigarettes. I don't even know why I cheated because it's not like anyone was watching. [Group 1 Participant 2]}

In another focus group, a similar sentiment arose:

...how is this going to know when I'm smoking a cigarette or not? I can just say I'm not...and then I'll be sitting there smoking a cig, you know. [Group 2 Participant 4]

Other participants felt that apps might have limited benefit without a method of confirming smoking status. One participant stated:

Like, the phone has to have a contact system where you're, like, Face-Timing somebody who's coming to visit you to go meet for coffee and then they're smelling you and they can see if you smoked any cigarettes by doing that test... [Group 2 Participant 3]

Despite general agreement that entering information into the app on an honor system is a limitation, participants who mentioned biochemical verification as a means to achieve this did so unfavorably. In one group, a participant described mistrust of the accuracy of breath carbon monoxide monitoring. In another focus group, a participant who mentioned concern about false reporting to the app went on to consider breath carbon monoxide monitoring, but then immediately discounted it, saying,

\section{...that's a little much... [Group 2 Participant 4]}

Participants made few recommendations about features that should be avoided in a smoking cessation app, but a common 
concern was the possibility that the app could trigger cravings. Based on their prior experiences with smoking triggers, they were concerned that any mention of cigarettes in the app could increase their desire to smoke:

You'd have to use, like a code word for cigarette so people don't think it in their heads because once they think 'cigarette,' they're more likely to smoke. [Group 2 Participant 3]

\section{Discussion}

\section{Principal Results and Comparison With Prior Work}

In this study, we explored the attitudes of young adults with serious mental illness who smoke toward quitting smoking and the use of apps for this purpose. Overall, our findings share significant overlap with those of prior early phase trials in middle-aged adults with serious mental illness [30,33]. We found that young adults with serious mental illness who smoke shared similar reasons for quitting or continuing to smoke as those in other populations and were interested in using apps during a quit or reduction attempt. Participants voiced a desire for apps to provide ongoing motivational content during a quit attempt, features to increase awareness of smoking habits and money spent, content that could be used as a distraction from smoking, reward features, and social support for quitting smoking. They also described potential app limitations, such as the temptation to enter false information into the tracking features, and an app's potential to trigger cravings. This group's concern about psychiatric side effects of cessation pharmacotherapy is an additional important characteristic that could be countered or monitored with digital technology.

Our analysis revealed a tension between participants' desire to see progress via tracking features and their fear of seeing personal failure via the same features. Similar to qualitative findings in studies of middle-aged adults with and without mental illness [30,33,42-44], participants in our study voiced a strong desire for cigarette- and money-tracking features that could demonstrate progress and enhance motivation during a quit attempt. However, participants also described using other apps with similar features that had not affected their patterns of behavior. Additionally, and similar to other adults with and without mental health issues $[33,45]$, they expressed concern that recording information that suggests a lack or loss of progress might be demotivating and could lead to relapse or to the temptation to enter false information into the app. Although tracking smoking and viewing progress were popular features noted by this study group and those in other research $[30,42,43,46]$, in one study of general population adult daily smokers [43], these features were not associated with improved abstinence.

Similar to other studies of adults with serious mental illness, in general $[10,12,13,33]$, and young people with mental health conditions, in particular [47], participants described their main barriers to quitting as inability to resist cravings, using smoking to manage mental health symptoms, and smoking out of habit. Yet, only a few suggested that apps could teach strategies to overcome these barriers. Instead, most participants conveyed the common perception that it just takes "will power" to quit, rather than the application of skills to tolerate stress and urges without smoking. Skills training, such as advice on changing routines and improving coping strategies for cravings, has been shown to improve abstinence outcomes for both in-person [48] and app-based [43] interventions. Taken together, these data suggest that tracking features are appealing and may enhance engagement or motivation, but other skill building or clinical support features for cessation skills would need to be prominent and engaging to ensure use within the apps.

Many participants in this study recommended that cessation apps include financial rewards or badges awarded by the app for progress. There is a growing body of literature to support the use of rewards in the form of praise [48] and financial incentives $[49,50]$ for smoking cessation. Inclusion of rewards features in smoking cessation apps, therefore, has promise to improve both engagement and abstinence outcomes.

While prior studies assessing users' desire for specific features in smoking cessation apps demonstrate mixed results regarding the role of social support for quitting within apps [33,42,44,45], participants in our study clearly valued this feature. In line with prior findings regarding the role of social influence on smoking behavior in people with serious mental illness [10,51], our participants highlighted the importance of the effects of social environment and peer interaction on their smoking behaviors and described the potential benefit of an alternative smoke-free support system within the app. They specifically voiced a desire for peer support through chat functions and competitions, as opposed to smoking cessation coaching or technology coaching that has been described in other studies [30,32]. This desire for peer support is similar to preferences described by young adults with serious mental illness in a study [52] assessing the possible role of digital support for mental health diagnoses and highlights the perceived importance of peer-to-peer interaction for overcoming the stigma and challenges associated with smoking as well as living with mental illness. Although one study [53] demonstrated the potential of a motivational intervention delivered by peers, Dickerson and colleagues [54] described numerous challenges to cessation associated with a peer mentoring approach for people with serious mental illness. While this feature may improve engagement in the app and promote overall well-being, its effect on smoking behaviors requires further study.

The landscape of smoking cessation apps is rapidly changing. Currently available apps are variable in their content and features [27,29,55-58], and few contain content that adheres to clinical practice guidelines [27,55-57,59-61]. A recent literature review [29] found that most smoking cessation apps included self-tracking features, but only one-third included social support and one-third included rewards systems. Furthermore, most apps included three or fewer features, which typically involved education, tracking, and a variable third feature [29]. Another recent review [58] found that less than half of available apps included advice on changing routines or coping with cravings. Apps that include high-quality, evidence-based content as well as an array of both desired features and features previously found to be effective should be tested in this population. 
Compared to other populations of smokers, the young adults with serious mental illness in this study voiced similar reasons for smoking, quitting smoking, and relapsing after a quit attempt $[34,62,63]$, but they expressed specific concerns regarding medication safety in relation to their mental health conditions. A wide body of evidence has demonstrated the safety and efficacy of cessation pharmacotherapy in the setting of mental illness [3,11,15-17]. Thus, improving utilization of these treatments can substantially impact quit rates. Our findings suggest that content in a smoking cessation app tailored for young adults with serious mental illness can likely overlap substantially with content in other smoking cessation apps, with additional information about medication safety for people with mental illness.

\section{Limitations}

Several study limitations merit consideration. First, participants were not required to be interested in quitting smoking in order to participate in the study; individuals who are actively engaged in an attempt to quit smoking may ultimately prefer different app features. Second, participants were predominantly White residents in a small New England city, and may not be representative of smokers with serious mental illness who have other demographic characteristics or are from other geographic regions. Yet the substantial overlap between our findings and those of research in other populations [30,33,42,43] supports the validity and generalizability of the themes conveyed here. Lastly, most participants had not previously used apps for smoking cessation, and therefore, relied on anticipated future desires for their responses. While anticipation of future desires can be subject to a number of biases, assessing participants' preferences prior to exposure to specific apps is important to understanding how they will appraise apps during initial use. Future work should assess responses to cessation apps in this population.

\section{Conclusions}

Young adults with serious mental illness expressed similar reasons for quitting smoking or continuing to smoke compared to those expressed by other populations of individuals who smoke, but low cessation treatment utilization rates and quit rates suggest that other treatment modalities are needed. Apps have the potential to support quit or reduction attempts for young adults with serious mental illness in a number of ways, such as providing ongoing motivation during a quit attempt, increasing awareness of smoking habits and money spent, and providing information and support for using cessation skills. However, while young adult with serious mental illness who smoke are interested in using apps, further tailoring, optimization, and clinical support may be necessary to effectively promote cessation in this population.

\section{Acknowledgments}

The authors would like to thank Susan Guarino and Jason Welsh for their assistance with recruiting participants. MAG's work is supported by National Institute on Drug Abuse (Grant Number P30DA029926) via a pilot award through the Center for Technology and Behavioral Health at Dartmouth, and by a Health Resources Services Administration postdoctoral fellowship grant (T32HP32520). MFB's work is supported by Substance Abuse and Mental Health Services Administration (Grant Number 1H79SM080245-01). These funding organizations had no involvement in the study design; the collection, analysis, or interpretation of the data; the preparation of the report; or the decision to submit the article for publication.

\section{Authors' Contributions}

MAG and MFB designed the study with qualitative expertise provided by MRL. MAG, NJK, and AEM collected data and performed data analysis, with oversight of these activities provided by MFB and MRL. MAG and MFB prepared the original draft of the manuscript. MFB, NJK, AEM, and MRL reviewed and provided comments on the manuscript before submission.

\section{Conflicts of Interest}

MFB has received research funding support from Alkermes. The other authors have no competing interests to declare.

\section{Multimedia Appendix 1}

Focus group discussion guide.

[DOCX File, 16 KB-Multimedia Appendix 1]

\section{References}

1. Smith PH, Mazure CM, McKee SA. Smoking and mental illness in the U.S. population. Tob Control 2014 Nov;23(e2):e147-e153 [FREE Full text] [doi: 10.1136/tobaccocontrol-2013-051466] [Medline: 24727731]

2. Wang TW, Asman K, Gentzke AS, Cullen KA, Holder-Hayes E, Reyes-Guzman C, et al. Tobacco product use among adults - United States, 2017. MMWR Morb Mortal Wkly Rep 2018 Nov 09;67(44):1225-1232 [FREE Full text] [doi: 10.15585/mmwr.mm6744a2] [Medline: $\underline{\text { 30408019] }}$

3. Anthenelli RM, Benowitz NL, West R, St Aubin L, McRae T, Lawrence D, et al. Neuropsychiatric safety and efficacy of varenicline, bupropion, and nicotine patch in smokers with and without psychiatric disorders (EAGLES): a double-blind, randomised, placebo-controlled clinical trial. The Lancet 2016 Jun;387(10037):2507-2520. [doi: 10.1016/s0140-6736(16)30272-0] 
4. Xu X, Bishop EE, Kennedy SM, Simpson SA, Pechacek TF. Annual healthcare spending attributable to cigarette smoking: an update. Am J Prev Med 2015 Mar;48(3):326-333 [FREE Full text] [doi: 10.1016/j.amepre.2014.10.012] [Medline: 25498551]

5. Walker ER, McGee RE, Druss BG. Mortality in mental disorders and global disease burden implications: a systematic review and meta-analysis. JAMA Psychiatry 2015 Apr;72(4):334-341 [FREE Full text] [doi:

10.1001/jamapsychiatry.2014.2502] [Medline: 25671328]

6. Chesney E, Goodwin G, Fazel S. Risks of all-cause and suicide mortality in mental disorders: a meta-review. World Psychiatry 2014 Jun;13(2):153-160 [FREE Full text] [doi: 10.1002/wps.20128] [Medline: 24890068]

7. Jha P, Ramasundarahettige C, Landsman V, Rostron B, Thun M, Anderson RN, et al. 21st-century hazards of smoking and benefits of cessation in the United States. N Engl J Med 2013 Jan 24;368(4):341-350. [doi: 10.1056/NEJMsa1211128] [Medline: 23343063]

8. Doll R, Peto R, Boreham J, Sutherland I. Mortality in relation to smoking: 50 years' observations on male British doctors. BMJ 2004 Jun 26;328(7455):1519 [FREE Full text] [doi: 10.1136/bmj.38142.554479.AE] [Medline: 15213107]

9. Ziedonis D, Hitsman B, Beckham JC, Zvolensky M, Adler LE, Audrain-McGovern J, et al. Tobacco use and cessation in psychiatric disorders: National Institute of Mental Health report. Nicotine Tob Res 2008 Dec;10(12):1691-1715. [doi: 10.1080/14622200802443569] [Medline: 19023823]

10. Tidey JW, Miller ME. Smoking cessation and reduction in people with chronic mental illness. BMJ 2015 Sep 21;351:h4065 [FREE Full text] [doi: 10.1136/bmj.h4065] [Medline: 26391240]

11. Cather C, Pachas GN, Cieslak KM, Evins AE. Achieving smoking cessation in individuals with schizophrenia: special considerations. CNS Drugs 2017 Jun;31(6):471-481 [FREE Full text] [doi: 10.1007/s40263-017-0438-8] [Medline: 28550660]

12. Lum A, Skelton E, Wynne O, Bonevski B. A systematic review of psychosocial barriers and facilitators to smoking cessation in people living with schizophrenia. Front Psychiatry 2018;9:565 [FREE Full text] [doi: 10.3389/fpsyt.2018.00565] [Medline: $\underline{30459658]}$

13. Trainor K, Leavey G. Barriers and facilitators to smoking cessation among people with severe mental illness: a critical appraisal of qualitative studies. Nicotine Tob Res 2017 Jan;19(1):14-23. [doi: 10.1093/ntr/ntw183] [Medline: 27613905]

14. Joffe RT, MacQueen GM, Marriott M, Robb J, Begin H, Young LT. Induction of mania and cycle acceleration in bipolar disorder: effect of different classes of antidepressant. Acta Psychiatr Scand 2002 Jun;105(6):427-430. [doi: 10.1034/j.1600-0447.2002.02360.x] [Medline: 12059846]

15. Tsoi DT, Porwal M, Webster AC. Interventions for smoking cessation and reduction in individuals with schizophrenia. Cochrane Database Syst Rev 2013;2:CD007253. [doi: 10.1002/14651858.CD007253.pub3] [Medline: 23450574]

16. Evins AE, Cather C, Pratt SA, Pachas GN, Hoeppner SS, Goff DC, et al. Maintenance treatment with varenicline for smoking cessation in patients with schizophrenia and bipolar disorder: a randomized clinical trial. JAMA 2014 Jan 08;311(2):145-154 [FREE Full text] [doi: 10.1001/jama.2013.285113] [Medline: 24399553]

17. George TP, Vessicchio JC, Sacco KA, Weinberger AH, Dudas MM, Allen TM, et al. A placebo-controlled trial of bupropion combined with nicotine patch for smoking cessation in schizophrenia. Biol Psychiatry 2008 Jun 01;63(11):1092-1096 [FREE Full text] [doi: 10.1016/j.biopsych.2007.11.002] [Medline: 18096137]

18. Fiore M, Jaén C, Baker T. Treating Tobacco Use and Dependence: 2008 Update. Rockville, MD: U.S. Department of Health and Human Services; May 2008.

19. Suls JM, Luger TM, Curry SJ, Mermelstein RJ, Sporer AK, An LC. Efficacy of smoking-cessation interventions for young adults: a meta-analysis. Am J Prev Med 2012 Jun;42(6):655-662 [FREE Full text] [doi: 10.1016/j.amepre.2012.02.013] [Medline: 22608385]

20. Villanti AC, McKay HS, Abrams DB, Holtgrave DR, Bowie JV. Smoking-cessation interventions for U.S. young adults: a systematic review. Am J Prev Med 2010 Dec;39(6):564-574. [doi: 10.1016/j.amepre.2010.08.009] [Medline: 21084078]

21. Marshall LL, Zhang L, Malarcher AM, Mann NH, King BA, Alexander RL. Race/ethnic variations in Quitline use among US adult tobacco users in 45 states, 2011-2013. Nicotine Tob Res 2017 Nov 07;19(12):1473-1481. [doi: 10.1093/ntr/ntw281] [Medline: 29121347]

22. National quitline data warehouse statistical brief. Smoking \& Tobacco Use.: Centers for Disease Control and Prevention; 2018 Apr 25. URL: https://www.cdc.gov/tobacco/quit smoking/cessation/nqdw/statistical-brief/index.htm [accessed 2020-01-28] [WebCite Cache ID https://www.cdc.gov/tobacco/quit_smoking/cessation/nqdw/statistical-brief/index.htm]

23. Brunette MF, Feiron JC, Aschbrenner K, Colctti D, Devitt T, Greene MA, et al. Characteristics and predictors of intention to use cessation treatment among smokers with schizophrenia: young adults compared to older adults. J Subst Abus Alcohol 2017;5(1) [FREE Full text] [Medline: 29881770]

24. Brunette MF, Ferron JC, Aschbrenner KA, Pratt SI, Geiger P, Kosydar S. Attitudes about smoking cessation treatment, intention to quit, and cessation treatment utilization among young adult smokers with severe mental illnesses. Addict Behav 2019 Feb;89:248-255 [FREE Full text] [doi: 10.1016/j.addbeh.2018.09.028] [Medline: 30343187]

25. Brunette MF, Ferron JC, Robinson D, Coletti D, Geiger P, Devitt T, et al. Brief web-based interventions for young adult smokers with severe mental illnesses: a randomized, controlled pilot study. Nicotine Tob Res 2018 Sep 04;20(10):1206-1214. [doi: 10.1093/ntr/ntx190] [Medline: 29059417] 
26. Mobile Fact Sheet. Pew Research Center. Washington D.C: Pew Research Center; 2018 Feb 05. URL: https://www. pewinternet.org/fact-sheet/mobile/

27. Hoeppner BB, Hoeppner SS, Seaboyer L, Schick MR, Wu GWY, Bergman BG, et al. How smart are smartphone apps for smoking cessation? a content analysis. Nicotine Tob Res 2015 Jun 4. [doi: 10.1093/ntr/ntv117] [Medline: 26045249]

28. Brunette M, Achtyes E, Pratt S, Stilwell K, Opperman M, Guarino S, et al. Use of smartphones, computers and social media among people with smi: opportunity for intervention. Community Ment Health J 2019 Jun 8;55(6):973-978. [doi: 10.1007/s10597-019-00431-7]

29. Vilardaga R, Casellas-Pujol E, McClernon JF, Garrison KA. Mobile applications for the treatment of tobacco use and dependence. Curr Addict Rep 2019 May 9;6(2):86-97. [doi: 10.1007/s40429-019-00248-0]

30. Vilardaga R, Rizo J, Kientz JA, McDonell MG, Ries RK, Sobel K. User experience evaluation of a smoking cessation app in people with serious mental illness. Nicotine Tob Res 2016 May;18(5):1032-1038. [doi: 10.1093/ntr/ntv256] [Medline: 26581430]

31. Vilardaga R, Rizo J, Ries RK, Kientz JA, Ziedonis DM, Hernandez K, et al. Formative, multimethod case studies of learn to quit, an acceptance and commitment therapy smoking cessation app designed for people with serious mental illness. Transl Behav Med 2019 Nov 25;9(6):1076-1086 [FREE Full text] [doi: 10.1093/tbm/iby097] [Medline: 30445507]

32. Vilardaga R, Rizo J, Zeng E, Kientz JA, Ries R, Otis C, et al. User-centered design of learn to quit, a smoking cessation smartphone app for people with serious mental illness. JMIR Serious Games 2018 Jan 16;6(1):e2 [FREE Full text] [doi: 10.2196/games.8881] [Medline: 29339346]

33. Klein P, Lawn S, Tsourtos G, van Agteren J. Tailoring of a smartphone smoking cessation app (kick.it) for serious mental illness populations: qualitative study. JMIR Hum Factors 2019 Sep 03;6(3):e14023 [FREE Full text] [doi: 10.2196/14023] [Medline: $\underline{31482850}$ ]

34. Villanti AC, Bover Manderski MT, Gundersen DA, Steinberg MB, Delnevo CD. Reasons to quit and barriers to quitting smoking in US young adults. Fam Pract 2016 Apr;33(2):133-139 [FREE Full text] [doi: 10.1093/fampra/cmv103] [Medline: 26733658]

35. Delnevo CD, Villanti AC, Wackowski OA, Gundersen DA, Giovenco DP. The influence of menthol, e-cigarettes and other tobacco products on young adults' self-reported changes in past year smoking. Tob Control 2016 Sep;25(5):571-574 [FREE Full text] [doi: 10.1136/tobaccocontrol-2015-052325] [Medline: 26243809]

36. Morgan D. Focus Groups as Qualitative Research Second Edition. Thousand Oaks, CA: SAGE Publications, Inc; 1997.

37. Morse JM. The significance of saturation. Qualitative Health Research 1995 May 01;5(2):147-149. [doi: $10.1177 / 104973239500500201]$

38. Guest G, Namey E, McKenna K. How many focus groups are enough? building an evidence base for nonprobability sample sizes. Field Methods 2016 Jul 24;29(1):3-22. [doi: 10.1177/1525822X16639015]

39. Braun V, Clarke V. Using thematic analysis in psychology. Qualitative Research in Psychology 2006 Jan;3(2):77-101. [doi: 10.1191/1478088706qp063oa]

40. Bradley EH, Curry LA, Devers KJ. Qualitative data analysis for health services research: developing taxonomy, themes, and theory. Health Serv Res 2007 Aug;42(4):1758-1772 [FREE Full text] [doi: 10.1111/j.1475-6773.2006.00684.x] [Medline: 17286625]

41. Padgett D. Qualitative and Mixed Methods in Public Health. Thousand Oaks, CA: SAGE Publications, Inc; 2012.

42. Oliver JA, Hallyburton MB, Pacek LR, Mitchell JT, Vilardaga R, Fuemmeler BF, et al. What do smokers want in a smartphone-based cessation application? Nicotine Tob Res 2017 Aug 03. [doi: 10.1093/ntr/ntx171] [Medline: 29065202]

43. Heffner JL, Vilardaga R, Mercer LD, Kientz JA, Bricker JB. Feature-level analysis of a novel smartphone application for smoking cessation. Am J Drug Alcohol Abuse 2015 Jan;41(1):68-73. [doi: 10.3109/00952990.2014.977486] [Medline: 25397860]

44. Paay J, Kjeldskov J, Skov MB, Lichon L, Rasmussen S. Understanding individual differences for tailored smoking cessation apps. New York, NY: Association for Computing Machinery; 2015 Presented at: CHI '15: Proceedings of the 33rd Annual ACM Conference on Human Factors in Computing Systems; April 2015; Seoul Republic of Korea p. 1699-1708. [doi: 10.1145/2702123.2702321]

45. Thornton LK, Kay-Lambkin FJ. Specific features of current and emerging mobile health apps: user views among people with and without mental health problems. mHealth 2018 Dec;4:56-56. [doi: 10.21037/mhealth.2018.11.04]

46. Iacoviello BM, Steinerman JR, Klein DB, Silver TL, Berger AG, Luo SX, et al. Clickotine, a personalized smartphone app for smoking cessation: initial evaluation. JMIR Mhealth Uhealth 2017 Apr 25;5(4):e56 [FREE Full text] [doi: 10.2196/mhealth.7226] [Medline: 28442453]

47. Prochaska JJ, Fromont SC, Wa C, Matlow R, Ramo DE, Hall SM. Tobacco use and its treatment among young people in mental health settings: a qualitative analysis. Nicotine Tob Res 2013 Aug;15(8):1427-1435 [FREE Full text] [doi: 10.1093/ntr/nts343] [Medline: 23322765]

48. West R, Walia A, Hyder N, Shahab L, Michie S. Behavior change techniques used by the English Stop Smoking Services and their associations with short-term quit outcomes. Nicotine Tob Res 2010 Jul;12(7):742-747. [doi: 10.1093/ntr/ntq074] [Medline: 20478957] 
49. Notley C, Gentry S, Livingstone-Banks J, Bauld L, Perera R, Hartmann-Boyce J. Incentives for smoking cessation. Cochrane Database of Systematic Reviews 2019;7. [doi: 10.1002/14651858.cd004307.pub6]

50. Brunette MF, Pratt SI, Bartels SJ, Scherer EA, Sigmon SC, Ferron JC, et al. Randomized trial of interventions for smoking cessation among Medicaid beneficiaries with mental illness. Psychiatr Serv 2018 Mar 01;69(3):274-280. [doi:

10.1176/appi.ps.201700245] [Medline: 29137560]

51. Grundy SM, Stone NJ, Bailey AL, Beam C, Birtcher KK, Blumenthal RS, et al. 2018

AHA/ACC/AACVPR/AAPA/ABC/ACPM/ADA/AGS/APhA/ASPC/NLA/PCNA guideline on the management of blood cholesterol: a report of the American College of Cardiology/American Heart Association task force on clinical practice guidelines. J Am Coll Cardiol 2019 Jun 25;73(24):e285-e350. [doi: 10.1016/j.jacc.2018.11.003] [Medline: $\underline{\text { 30423393] }}$

52. Aschbrenner KA, Naslund JA, Tomlinson EF, Kinney A, Pratt SI, Brunette MF. Adolescents' use of digital technologies and preferences for mobile health coaching in public mental health settings. Front Public Health 2019;7:178 [FREE Full text] [doi: 10.3389/fpubh.2019.00178] [Medline: $\underline{31312629}$ ]

53. Williams JM, Dwyer M, Verna M, Zimmermann MH, Gandhi KK, Galazyn M, et al. Evaluation of the CHOICES program of peer-to-peer tobacco education and advocacy. Community Ment Health J 2011 Jun;47(3):243-251. [doi: 10.1007/s10597-010-9310-8] [Medline: 20419349]

54. Dickerson F, Savage CLG, Schweinfurth LAB, Goldberg RW, Bennett M, Dixon L, et al. The experience of peer mentors in an intervention to promote smoking cessation in persons with psychiatric illness. Community Ment Health J 2016 May;52(4):416-423 [FREE Full text] [doi: 10.1007/s10597-015-9967-0] [Medline: 26602772]

55. Ferron JC, Brunette MF, Geiger P, Marsch LA, Adachi-Mejia AM, Bartels SJ. Mobile phone apps for smoking cessation: quality and usability among smokers with psychosis. JMIR Hum Factors 2017 Mar 03;4(1):e7 [FREE Full text] [doi: 10.2196/humanfactors.5933] [Medline: 28258047]

56. Haskins BL, Lesperance D, Gibbons P, Boudreaux ED. A systematic review of smartphone applications for smoking cessation. Transl Behav Med 2017 Jun;7(2):292-299 [FREE Full text] [doi: 10.1007/s13142-017-0492-2] [Medline: 28527027]

57. Robinson CD, Seaman EL, Grenen E, Montgomery L, Yockey RA, Coa K, et al. A content analysis of smartphone apps for adolescent smoking cessation. Transl Behav Med 2020 Feb 03;10(1):302-309. [doi: 10.1093/tbm/iby113] [Medline: $\underline{30476293}$ ]

58. Ubhi HK, Michie S, Kotz D, van SOCP, Selladurai A, West R. Characterising smoking cessation smartphone applications in terms of behaviour change techniques, engagement and ease-of-use features. Transl Behav Med 2016 Sep;6(3):410-417 [FREE Full text] [doi: 10.1007/s13142-015-0352-x] [Medline: 27528530]

59. Abroms LC, Padmanabhan N, Thaweethai L, Phillips T. iPhone apps for smoking cessation: a content analysis. Am J Prev Med 2011 Mar;40(3):279-285 [FREE Full text] [doi: 10.1016/j.amepre.2010.10.032] [Medline: 21335258]

60. Abroms LC, Lee WJ, Bontemps-Jones J, Ramani R, Mellerson J. A content analysis of popular smartphone apps for smoking cessation. Am J Prev Med 2013 Dec;45(6):732-736 [FREE Full text] [doi: 10.1016/j.amepre.2013.07.008] [Medline: 24237915]

61. Thornton L, Quinn C, Birrell L, Guillaumier A, Shaw B, Forbes E, et al. Free smoking cessation mobile apps available in Australia: a quality review and content analysis. Aust N Z J Public Health 2017 Dec;41(6):625-630. [doi: 10.1111/1753-6405.12688] [Medline: 28749591]

62. Twyman L, Bonevski B, Paul C, Bryant J. Perceived barriers to smoking cessation in selected vulnerable groups: a systematic review of the qualitative and quantitative literature. BMJ Open 2014 Dec 22;4(12):e006414 [FREE Full text] [doi: 10.1136/bmjopen-2014-006414] [Medline: 25534212]

63. McCaul KD, Hockemeyer JR, Johnson RJ, Zetocha K, Quinlan K, Glasgow RE. Motivation to quit using cigarettes: a review. Addict Behav 2006 Jan;31(1):42-56. [doi: 10.1016/j.addbeh.2005.04.004] [Medline: 15916861]

Edited by G Eysenbach; submitted 05.05.20; peer-reviewed by E Grenen, S Lawn; comments to author 16.07.20; revised version
received 14.08.20; accepted 17.08.20; published 02.10.20
Please cite as:
Gowarty MA, Kung NJ, Maher AE, Longacre MR, Brunette MF
Perceptions of Mobile Apps for Smoking Cessation Among Young People in Community Mental Health Care: Qualitative Study
JMIR Form Res 2020;4(10):e19860
URL: $\underline{\text { https://formative.jmir.org/2020/10/e19860 }}$
doi: $10.2196 / 19860$
PMID: $\underline{3006560}$

CMinda A Gowarty, Nathan J Kung, Ashley E Maher, Meghan R Longacre, Mary F Brunette. Originally published in JMIR Formative Research (http://formative.jmir.org), 02.10.2020. This is an open-access article distributed under the terms of the 
Creative Commons Attribution License (https://creativecommons.org/licenses/by/4.0/), which permits unrestricted use, distribution, and reproduction in any medium, provided the original work, first published in JMIR Formative Research, is properly cited. The complete bibliographic information, a link to the original publication on http://formative.jmir.org, as well as this copyright and license information must be included. 